\title{
Cenários e perspectivas para o setor de saneamento e SUA INTERFACE COM OS RECURSOS HÍDRICOS
}

\author{
SCENERIES AND PERSPECTIVES FOR SANITATION SECTOR AND ITS INTERFACE \\ WITH THE HYDRIC RESOURCES SECTOR
}

\author{
SIMONE ALVES DE FARIA \\ Mestre em Desenvolvimento Sustentável - UnB \\ RICARDO COELHO DE FARIA \\ Doutor em Economia. Professor da Universidade Católica de Brasília
}

Recebido: 05/09/03 Aceito: 16/06/04

\begin{abstract}
RESUMO
Este artigo faz uma análise das perspectivas para o setor de saneamento com base em seu modelo de gestão e sua interface com o setor de recursos hídricos. Nessa análise são considerados dois cenários alternativos. No primeiro, não ocorre mudança institucional e legal significativa no atual modelo de gestão de saneamento. No segundo, supõe-se a aprovação do Projeto de Lei n. ${ }^{0} 4.147 / 2001$, que institui diretrizes nacionais para o saneamento e prevê a colaboração da Agência Nacional de Águas (ANA) para o setor. Em ambos os casos, verifica-se que existem limitaçōes em termos de um novo modelo de gestão.
\end{abstract}

PALAVRAS-CHAVE: Saneamento, recursos hídricos, regulação, gestão pública.

\section{INTRODUÇÃO}

A partir do início dos anos 90, se fortalece no Brasil o consenso acerca da necessidade de uma profunda reforma do Estado, incluindo reformas no campo fiscal, na previdência social e no próprio modelo administrativo do Estado. Em termos de reforma gerencial, a proposta que vem sendo implementada nos últimos anos é constituir um Estado que seja "enxuto" num certo sentido e, ao mesmo tempo, capaz de desempenhar as suas funçōes básicas relacionadas com a saúde, educação, habitação e proporcionar qualidade de vida para sociedade (Pereira, 1997).

De acordo com essa nova concepção, alguns setores tradicionalmente administrados diretamente pelo Estado passam a ser privatizados ou explorados pelo setor privado mediante concessão públi$\mathrm{ca}$, caracterizando a mudança de um Estado produtor para um Estado regulador. A privatização ou a concessão de al- guns setores importantes requer o desenho de um modelo adequado de regulação. Dentro dessa tese geral, este artigo discute as perspectivas para o setor de saneamento com base em seu atual modelo de gestão, bem como as reformas necessárias e a sua interface com os recursos hídricos.

A interface do setor de recursos hídricos com outros setores tem sido abordada por diversos autores. Numa perspectiva mais geral, Muñoz (2000) discute as razôes que justificam um debate entre o setor de recursos hídricos e outros setores intimamente correlacionados. Pagnoccheschi (2000) discute a política de recursos hídricos vis a vis a política de energia, de irrigação, de saneamento, de saúde, bem como suas inter-relações com os estados. Azevedo e Baltar (2000) apontam a necessidade de maior coordenação intersetorial da política de recursos hídricos, sobretudo com os setores de meio ambiente e saneamento. Mais especificamente, Pereira e Baltar (2000) siste- matizam as discussões havidas no período de 1992 a 1998 com relação ao debate sobre interfaces entre recursos hídricos e saneamento.

Os setores de abastecimento de água e de esgotamento sanitário têm feito parte da agenda política de países em desenvolvimento. São caracterizados por baixos índices de cobertura e de qualidade dos serviços. Diante desse quadro, diversos estudos têm procurado abordar as dificuldades encontradas na reforma e identificar os elementos essenciais para o seu sucesso das mudanças (Faria, Nogueira e Muller, 2003). No Brasil, pode-se destacar os estudos da INFUB (1995), Emerciano e Baltar (1995), Pereira, Baltar e Abicallil (1995), Rezende et al (1995), Aliança Pesquisa e Desenvolvimento (1995) e Parlatore (2000).

Este artigo contribui, portanto, com o debate sobre o tema tomando como base dois cenários: no primeiro, o atual modelo de gestão do setor de saneamento é mantido e, no segundo, supõe-se a 


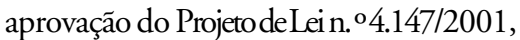
que institui diretriz nacional para o saneamento e prevê a participação da Agência Nacional de Águas na política do setor. $\mathrm{Na}$ segunda seção é feita uma breve descrição dos atuais modelos de gestão dos setores de saneamento e de recursos hídricos e, na terceira, os dois cenários propostos são discutidos com a finalidade de elucidar algumas preocupaçōes. Na última seção, as consideraçōes finais são feitas a título de conclusão do trabalho.

\section{OS ATUAIS MODELOS DE GESTÃO DOS SETORES DE RECURSOS HÍDRICOS E DE SANEAMENTO}

Esta seção tem a finalidade de descrever os atuais modelos de gestão pública dos setores de saneamento e de recursos hídricos no âmbito da Uniāo, destacando os principais órgãos federais envolvidos, bem como os aspectos legais e institucionais que compõem cada setor. A Figura 1 apresenta uma visão geral da estrutura organizacional básica de ambos os setores. Dentro desse propósito, esses modelos serão descritos separadamente nas subseções abaixo.

\section{O setor de recursos hídricos}

O grande marco histórico da política nacional de recursos hídricos data de 1934, com o Decreto Federal n. ${ }^{\circ} 24.643$, de 10.07.1934, o Código de Águas. Esse Código preconizava assegurar o uso gratuito de qualquer corrente ou nascente de água para as primeiras necessidades $\mathrm{da}$ vida de qualquer indivíduo, desde que obedecesse aos regulamentos administrativos. Estabeleceu como prioridade o abastecimento humano e considerou ilícito qualquer tipo de contaminação da água que prejudique a terceiros, responsabilizando os infratores pelo dano.

Inicialmente, a competência sobre os recursos hídricos, definida pelo Código de Águas, ficou a cargo do Ministério da Agricultura. No âmbito das prioridades, fica claro que o setor agrícola foi bastante beneficiado neste momento. A partir da década de 50 , essa competência foi transferida para o Ministério de Minas e Energia (MME). No setor elétrico, as atribuiçōes governamentais sobre recursos hídricos subordinaramse ao Departamento Nacional de Águas e Energia Elétrica (DNAEE), que era um órgão da administração direta, vinculado ao MME (Pagnoccheschi, 2000).
A supremacia do MME gerou insatisfaçōes em vários setores que dependiam da água como insumo para as suas atividades. O setor de irrigação, por exemplo, que na época era localizado no âmbito do Ministério do Interior, foi um dos que mais reagiu contra a hegemonia do setor elétrico. Apesar dessas insatisfaçôes, a ligação entre o setor elétrico e o de recursos hídricos permaneceu até o ano de 1995, quando foi criada a Secretaria de Recursos Hídricos (SRH) no âmbito do Ministério do Meio Ambiente -MMA (Pagnocchesci, 2000).

Do ponto de vista legal e institucional, pode-se dizer que o atual modelo de gestão dos recursos hídricos começou a ser moldado a partir dos dispositivos da nova Constituição de 1988. Com relação aos recursos hídricos, é o Art. 21 que atribui à União a competência de instituir o sistema nacional de gerenciamento de recursos hídricos, bem como definir critérios de outorga e de direitos de uso. Outro ponto igualmente importante é o Artigo 20 da Constituição Federal: "Pertencem à União os lagos, riose quaisquer correntes de água em terrenos de seu dominio, ou que banhem mais de um estado, sirvam de limites com outros países, ou se estendem a território estrangeiro ou dele provenham". Assim, as demais águas são de domínio dos estados. Dentro dessa nova ordem constitucional, deixam de existir as águas comuns, as municipais e as particulares. Então, se todas as águas pertencem à União e aos estados, de acordo com o Código Civil, isso faz com que elas sejam incluídas na categoria de bens públicos de uso comum. Com isso, as águas não são susceptíveis de direito de propriedade, embora o poder público possa conceder direito de uso a particulares (Carrera-Fernandez, 2000).

A Constituição Federal de 1988 encarregou ao Poder Executivo a responsabilidade de elaborar uma proposta específica de um Sistema Nacional de Gestão de Recursos Hídricos. Configurouse, então, o início de um longo processo para se chegar à elaboração da atual Lei de Águas do país: a Lei 9.433/97. Essa legislação representa, segundo Pagnocchesci (2000), um novo marco referencial no desenvolvimento da gestão dos recursos hídricos no país e permite adaptaçōes às diferentes situaçōes existentes nos Estados brasileiros, uma vez que alguns já tinham as suas próprias leis elaboradas, amparadas também pelos dispositivos constitucionais. Estados como São Paulo, Ceará, Distrito Federal, Minas
Gerais, entre outros, tiveram as suas leis aprovadas ainda na primeira metade da década de 90 (Kettelhut et al. 1999).

A legislação federal define os fundamentos, as diretrizes e os instrumentos de implantação de uma política de regulação do uso dos recursos hídricos no país. O seu principal objetivo é garantir o uso racional e integrado dos recursos hídricos, bem como assegurar não só à atual, mas às futuras gerações, a disponibilidade de água com padrōes aceitáveis de qualidade. A Política Nacional de Recursos Hídricos está fundamentada numa gestão descentralizada dos recursos hídricos, por bacia hidrográfica, na qual haja um envolvimento não só do Poder Público, mas de todos os usuários. Reconhece a água como um bem público de disponibilidade limitada em algumas áreas e dotado de valor econômico. A bacia hidrográfica é definida como a unidade territorial a ser considerada para implementação da Política Nacional de Recursos Hídricos, com a atuação do Sistema Nacional de Gerenciamento de Recursos Hídricos (SNGRH).

Um dos principais componentes do SNGRH é o Conselho Nacional de Recursos Hídricos (CNRH), que é o órgão máximo normativo e deliberativo. Engloba competências decisórias e articuladoras fundamentais para a atual Política Nacional de Recursos Hídricos. A Secretaria de Recursos Hídricos (SRH), do Ministério do Meio Ambiente, atua como Secretaria Executiva do CNRH. O CNRH é composto por representantes dos Ministérios e Secretarias da Presidência da República com atuação no gerenciamento ou no uso de recursos hídricos; representantes indicados pelos Conselhos Estaduais de Recursos Hídricos; representantes dos usuários dos recursos hídricos e representantes das organizaçōes civis de recursos hídricos.

O principal órgão executor da Política Nacional de Recursos Hídricos é a ANA - Agência Nacional de Águas. Esta agência é uma autarquia vinculada ao Ministério do Meio Ambiente e que funciona sob regime especial, com autonomia administrativa e financeira. A ANA obedecerá aos fundamentos, objetivos, diretrizes e instrumentos da Política $\mathrm{Na}$ cional de Recursos Hídricos, que se desenvolverá de maneira articulada com órgãos e entidades públicas e privadas integrantes do Sistema Nacional de Gerenciamento de Recursos Hídricos, tendo, dentre outras, as seguintes atribuiçōes: i) supervisionar, controlar e avaliar as ações e atividades decorrentes do cumprimento 


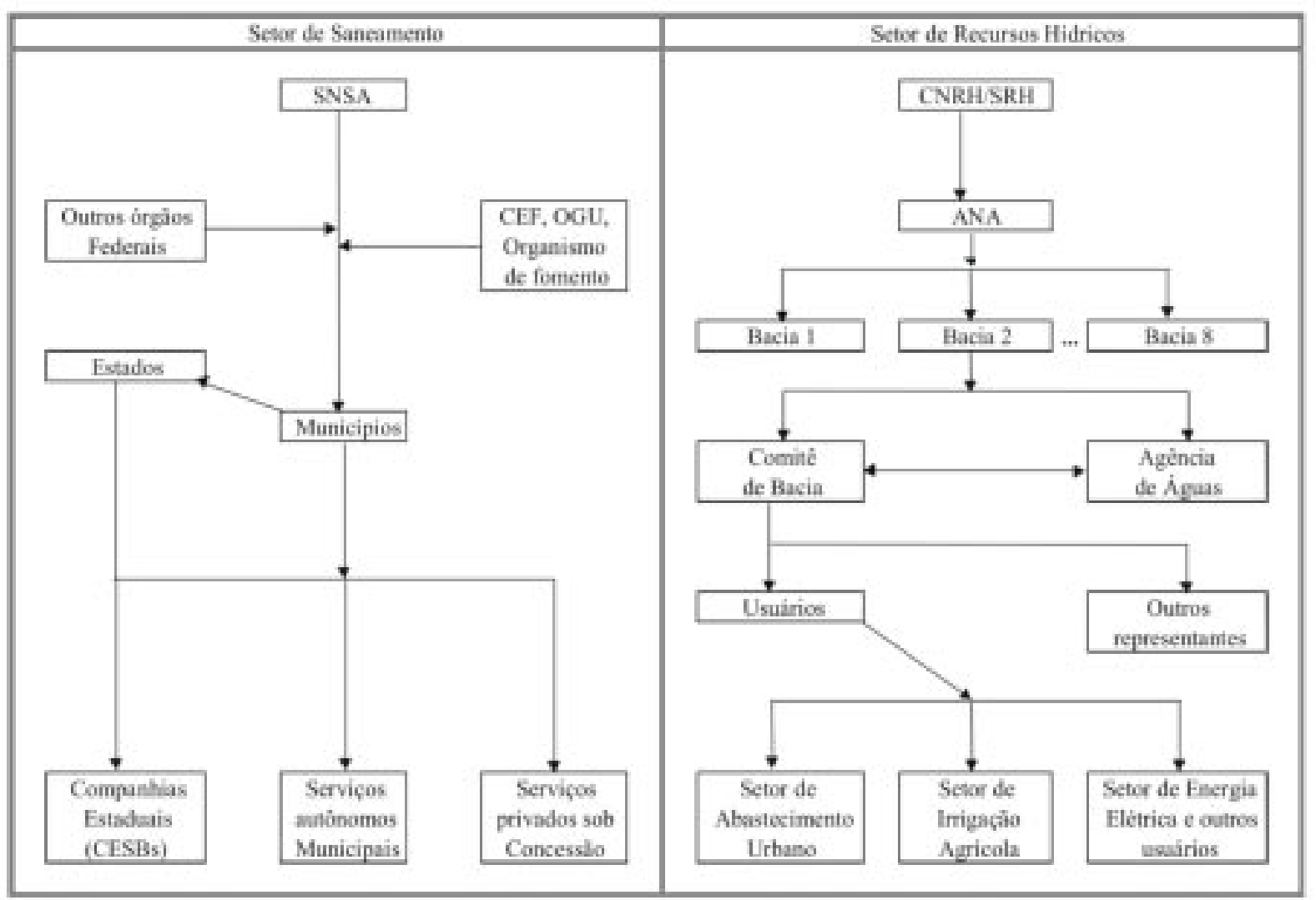

Fonte: elaboração dos autores

Figura I - Modelos de gestão pública dos setores de saneamento e de recursos hídricos

da legislação federal pertinente aos recursos hídricos; ii) implementar os instrumentos da Política Nacional de Recursos Hídricos; iii) outorgar, por intermédio de autorização, o direito de uso dos corpos de água de domínio da União; iv) implementar, em articulação com os Comitês de Bacia Hidrográfica, a cobrança pelo uso de recursos hídricos de domínio da União; v) participar da elaboração do Plano Nacional de Recursos Hídricos e supervisionar a sua implementação ${ }^{1}$.

De acordo com a Lei de Águas, “ $a$ bacia hidrográfica é a unidade territorial para implementação da Política Nacional de Recursos Hidricos e atuação do Sistema Nacional de Gerenciamento de Recursos Hidricos". Cada bacia hidrográfica deverá ter um Comitê de Bacia Hidrográfica e uma Agência de Água. Os Comitês de Bacia Hidrográfica atuarão no âmbito de cada bacia, mesmo, quando houver bacias hidrográficas contíguas (bacias vizinhas que têm uma fronteira comum, tais como a Bacia do Amazonas e a Bacia do Tocantins). Têm como principais atribuiçôes: promover o debate das questôes relacionadas a recursos hídricos e articular a atuação das entidades intervenientes; arbitrar os conflitos em primeira instância administrativa; aprovar o Plano de Recursos Hídricos da bacia; acompanhar a execução do Plano de Recursos Hídricos; estabelecer os mecanismos de cobrança pelo uso dos recursos hídricos. Estes Comitês são fóruns de discussão e de decisão sobre os projetos, programas e intervenções a serem feitas na área da bacia hidrográfica e representam o próprio parlamento das águas em sua região de abrangência ${ }^{2}$.

Os Comitês de Bacia Hidrográfica terão como secretaria executiva as Agências de Água. A existência das Agências de Água dependerá da existência prévia dos Comitês e da viabilidade financeira assegurada pela cobrança do uso dos recursos hídricos em sua área de atuação. A atuação da Agência de Água será a mesma dos Comitês, podendo atuar em um ou mais Comitês.

Segundo Muñoz (2000), esse novo modelo institucionaliza uma gestão participativa não só entre os níveis estadual e federal, mas também em nível de base representado pelos diversos usuários. Preconiza um processo de negociação contínuo entre os representantes dos diversos interesses em conflito e representa um grande avanço na gestão de recursos hídricos do país ao prever uma gestão por bacias hidrográficas.

\section{O setor de saneamento}

Embora os setores de abastecimento de água e de esgotamento sanitário sejam tradicionalmente um dos principais usuários dos recursos hídricos, historica-

${ }^{1}$ Maiores detalhes sobre as atribuições da ANA podem ser consultados no Art. 4 da Lei 9.984/2000.

${ }^{2}$ Nos casos de bacias de rios fronteiriços e transfonteiriços, os Comitês de Bacia Hum ográfica terão uma gestão compartilhada, sendo necessário, no âmbito da Uniāo, a participação de um representante do Ministério das Relaçôes Exteriores. Quando as bacias envolverem terras indígenas, os Comitês de Bacia terão que ter representantes da FUNAI e das comunidades indígenas ali residentes. 
mente a sua política tem sido desvinculada da política de águas. Durante anos a política pública que vigorou no país para o setor de saneamento teve como base o modelo do Plano Nacional de Saneamento Básico - PLANASA (1971-1992). O PLANASA constituiu um modelo de gestão centralizado de política de abastecimento urbano de água e esgoto e tinha o Banco Nacional de Habitação (BNH) como órgão executor. Os recursos financeiros eram originados do Fundo de Garantia por Tempo de Serviço (FGTS), do Orçamento Geral da União (OGU), dos Estados e dos municípios, bem como do próprio $\mathrm{BNH}$, de empréstimos externos junto a agências multilaterais de fomento e empréstimos internos. A coordenação e o planejamento da política de saneamento básico passou a ser realizada a nível nacional (INFURB, 1995). O PLANASA tinha como principais objetivos: aumentar cobertura dos serviços de abastecimento urbano de água e coleta de esgotos em um curto espaço de tempo, instituir uma política tarifária com valores reais para o setor de saneamento e concentrar a prestação dos serviços sob a coordenação das Companhias Estaduais de Saneamento Básico (CESBs).

O PLANASA representou um grande marco do crescimento dos índices de abastecimento de água e, em menor grau, da coleta de esgotos no país. Entre os anos de 1970-1980, o número de pessoas beneficiadas com o abastecimento de água passou de 11,9 milhões para 49,6 milhões. Já com relação ao esgotamento sanitário, apesar de mais modestos, os números mostram um melhora no atendimento, que passa de 6,1 milhões para 17,4 milhões de pessoas atendidas (Pagnoccheschi, 2000).

O período de 1990/94 é caracterizado pelas novas diretrizes econômicas e pela extinção do PLANASA (efetivada em $1992)^{3}$. Dentre as políticas públicas relevantes para o setor de saneamento nesse período, destacam-se: i) as reformas administrativas; ii) os novos programas criados pelo Conselho Curador do FGTS; iii) a extinção do controle das tarifas de água e esgoto; iv) aplicação de elevado volume de recursos a fundo perdido pelo orçamento federal no triênio 1991/93 (INFURB, 1995). Dentre os programas criados, destaca-se o Plano de Ação Imediata de Saneamento, coordenado pela
Secretaria Nacional de Saneamento do Ministério da Ação Social, tendo como suporte financeiro os recursos da Caixa Econômica Federal. Este Plano era formado por três programas: o Programa de Saneamento para Núcleos Urbanos (PRONURB), o Programa de Saneamento para População de Baixa Renda (PROSANEAR) e o Programa Social de Emergência e Geração de Empregos (PROSEGUE).

Em termos institucionais, várias reformas administrativas ocorreram no período, mas sem que houvessem produzido resultados significativos na melhoria do sistema. No governo Collor foi extinto o Ministério do Interior e criado o Ministério da Ação Social (MAS), que passou a incorporar as secretarias nacionais de Habitação e de Saneamento. O Conselho Curador do FGTS, enquanto isso, ficou localizado no Ministério do Trabalho e da Previdência Social, sendo que a Caixa Econômica Federal permaneceu no Ministério da Economia, Fazenda e Planejamento (INFURB, 1995).

A partir de 1995, inicia-se uma nova fase política no setor, caracterizada pela busca de um novo padrão de intervenção do Estado. A aprovação da Lei das Concessões (Lei 8.987/95) abre novas perspectivas de mudanças e amplia o espaço à flexibilização de prestação de serviços públicos. É nesse contexto de mudança do padrão de intervenção do Estado que surge a Nova Política Nacional de Saneamento, cujo princípio básico está na intenção da União em atuar, sobretudo, como reguladora, articuladora e promotora das questôes relacionadas às políticas de saneamento. Outros princípios básicos, como a universalização do atendimento, a participação de diversos agentes envolvidos na formulação da política de saneamento, bem como a descentralização dos serviços, compóem o pilar filosófico da atual política do setor.

No início desse período, a responsabilidade da política de saneamento ficou a cargo da Secretaria de Política UrbanaSEPURB - no âmbito do Ministério do Planejamento, que mais tarde, em 1999, foi transformada na atual Secretaria Especial de Desenvolvimento Urbano SEDU, vinculada diretamente à Presidência da República. No governo Lula esta secretaria foi transformada na atual Secretaria Nacional de Saneamento
Ambiental (SNSA) e incorporada no Ministério das Cidades, também criado por este governo. Além da SNSA, diversos órgãos federais atuam no setor: Ministério da Saúde (principalmente por meio da FUNASA - Fundação Nacional da Saúde), Ministério do Meio Ambiente, Recursos Hídricos e Amazônia Legal (por meio da ANA) e Caixa Econômica Federal - CEF (como agente financeiro). Além de coordenar e articular as ações e programas desses ministérios, a SNSA tem a incumbência de promover a parceria entre estados, municípios e setor privado (Figura 1).

De acordo com a Constituição de 1988, compete aos municípios organizar e prestar diretamente, ou sob o regime de concessão ou permissão, os serviços públicos de interesse local, incluindo, sob certas condiçôes, o saneamento básico. Então, dentro desse arcabouço legalinstitucional, o município pode prestar os seus serviços diretamente (por meio de Departamentos ou Serviços Autônomos de Água e Esgoto) ou indiretamente, por meio de concessões às CESBs (como sugerido no PLANASA) ou a empresas privadas que se encarreguem do abastecimento e do sistema de esgotamento sanitário (Figura 1).

Atualmente, os serviços de saneamento no país são prestados mediante essas três modalidades, muito embora as Companhias Estaduais de Saneamento Básico (CESBs) ainda sejam responsáveis pelo atendimento da maior parte dos municípios. Apenas como ilustração, a Tabela 1 apresenta uma amostra de 198 prestadores de serviços que foi levantada pelo Diagnóstico dos Serviços de Água e Esgotos de 1999, do Sistema Nacional de Informaçôes sobre Saneamento (SNIS). De acordo com a classificação do SNIS, os prestadores de serviços de abrangência regional são constituídos pelas 27 companhias estaduais, responsáveis pelo abastecimento de água de mais de 3.800 municípios em todo o país.

Dentro dessa classificação, os prestadores de serviços de abrangência microrregional incluem aqueles serviços que operam um único conjunto de sistemas de um pequeno número de municípios. Já os serviços locais são constituídos por aqueles que atendem a um único município, mesmo que mediante a operação de mais de um sistema. Embora a Tabela 1

${ }^{3}$ A extinção do PLANASA foi caracterizada por uma desestruturação nas bases do modelo, provocada por alguns fatores tais como o desequilíbrio financeiro proveniente da inadimplência das CESBs, a não-adesão ao modelo por alguns municípios de porte médio das Regiōes Sul e Sudeste, a redução das transferências a fundo perdido da União para o Sistema Financeiro do Saneamento (SFS) e os problemas de manutenção das tarifas em valores reais (INFURB, 1995). 
Tabela I - Brasil: Distribuição dos prestadores de serviços de águas e esgotos, segundo sua área de abrangência e características do atendimento, situação em 1999

\begin{tabular}{cccccc}
\hline Prestadores de Serviços & \multicolumn{2}{c}{$\begin{array}{c}\text { População urbana dos } \\
\text { Municípios atendidos }\end{array}$} & \multicolumn{2}{c}{ Quantidade de } \\
Municípios atendidos \\
Abrangência & Quant. & $\begin{array}{c}\text { Água } \\
\text { (milhōes) }\end{array}$ & $\begin{array}{c}\text { Esgoto } \\
\text { (milhōes) }\end{array}$ & Água & Esgoto \\
\hline Regional $\left(^{*}\right)$ & 27 & 100,6 & 69,5 & 3.890 & 748 \\
Microrregional & 5 & 0,8 & 0,1 & 14 & 4 \\
Local & 166 & 18,9 & 17,4 & 165 & 100 \\
Total & 198 & 120,3 & 98,0 & 4.069 & 852 \\
\hline
\end{tabular}

Fonte: Diagnóstico dos Serviços de Água e Esgotos - 1999/Sistema Nacional de Informaçōes sobre Saneamento - SNIS.

${ }^{*}$ Inclui 26 companhias estaduais e uma autarquia estadual.

não identifique os serviços concedidos ao setor privado, informaçōes da $\mathrm{ABCON}$ (Associação Brasileira das Concessionárias de Serviços Públicos de Águas e Esgoto) indicam que existem atualmente 35 consórcios de operadoras privadas que atuam em cerca de 53 municípios em todo o país (Faria, Nogueira e Mueller, 2003) 4 .

Em suma, o atual modelo de gestão do setor de saneamento pode ser caracterizado por dois aspectos gerais. Primeiro, pela flexibilidade nas formas em que o município pode prestar os serviços de saneamento básico (diretamente por meio de alguma instituição municipal, por meio de concessão à Companhia Estadual ou concessão ao setor privado). Segundo, pela ausência de um marco regulatório melhor definido que possa dar suporte a essas diferentes formas possíveis de prestação dos serviços, o que será discutido na próxima seção.

\section{CENÁRIOS E PERSPECTIVAS PARA O SETOR DE SANEAMENTO}

A formulação e a concretização de um novo modelo institucional para a Política Nacional de Saneamento requer, ain$\mathrm{da}$, instrumentos jurídicos-legais e normativos. Dentre eles, o próprio documento de intenções da antiga SEDU destaca $^{5}$ : i) necessidade de uma lei que trate da cooperação entre as esferas do governo e entre estas e a sociedade, no âmbito das competências comuns em matéria de saneamento; ii) um conjunto de instru- mentos que disponha sobre a criação e o funcionamento de um sistema de financiamento e gestão de recursos da União para aplicaçōes em saneamento; iii) legislação específica para regular as empresas prestadoras de serviços de saneamento; iv) normas e regulamentos referentes às relaçóes contratuais para prestação dos serviços; e v) revisão dos mecanismos tarifários e de subsídios.

Então, de acordo com esses instrumentos jurídicos-legais e normativos, as perspectivas para o setor de saneamento são analisadas tomando-se como base dois cenários: no primeiro, esses instrumentos não são levados adiante e o modelo de gestão permanece como está; no segundo, supõe-se a aprovação do projeto Lei 4.147/2001, que institui diretriz nacional para o saneamento básico e prevê a normatização desses instrumentos, incluindo a participação da ANA na política de saneamento.

\section{Cenário 1: o status quo}

A permanência do atual modelo de gestão do setor de saneamento elucida algumas preocupaçôes. O primeiro ponto se refere à competência na área de saneamento. Em decorrência de suas interfaces com os problemas de saúde, recursos hídricose meio ambiente, as atividades de saneamento básico terminam por constituir uma competência comum entre União, estados e municípios, de acordo com o ordenamento jurídico definido pela Constituição de 1988 (Holanda et al, 1995).
Mais especificamente, esses dispositivos constitucionais são os seguintes. De acordo com o Art. 21 (inciso XX), compete à União instituir diretrizes para o desenvolvimento urbano, inclusive habitação, saneamento básico e transportes urbanos. Pelo Art. 23, é competência comum da União, dos estados, do Distrito Federal e dos municípios, promover programas de construção de moradia e a melhoria das condiçōes habitacionais e de saneamento básico. Com base no Art. 200, o Sistema Único de Saúde, além de outras atribuiçōes, deve participar da formulação da política de saneamento básico. O Art. 30, por sua vez, estabelece que compete aos municípios organizar e prestar, diretamente ou sob regime de concessão ou permissão, os serviços públicos de interesse local.

O texto constitucional deixa claro, portanto, a necessidade de uma legislação complementar para o estabelecimento das formas de cooperação entre as três esferas de poder, o que está previsto, inclusive, no Art. 23 (Parágrafo Único). Não há na Constituição uma referência explícita ao poder concedente dos municípios sobre os serviços, embora uma interpretação possível seria enquadrar as açôes de abastecimento de água e de esgotamento sanitário na categoria de "serviços públicos de interesse local", o que daria a titularidade dos serviços aos municípios (IESP, 1995).

Caso uma legislação complementar acerca da competência comum não venha a ser instituída, não significa, necessariamente, um caos para o setor. Como avalia a INFURB (1995), esse tipo de competência cobre as possibilidades de prestação dos serviços de atividade pública do saneamento, incluindo as açôes complementares ou supletivas correspondentes. Isto significa que, em relação à melhoria das condições de saneamento básico, o estado ou a União pode, sem ofender a autonomia municipal, promover medidas destinadas a completar ou a suprir os serviços de saneamento, atendendo adequadamente a população a que se destinam.

No entanto, como também observa a INFURB (1995), é preciso considerar os potenciais conflitos existentes em função das indefiniçōes das atribuições de cada esfera do governo, especialmente entre estados e municípios. Por exemplo: a) se o município presta o serviço adequadamente, é possivel acumular o exer-

\footnotetext{
${ }^{4}$ Esse número de consórcios está baseado em informações atualizadas da ABCON em setembro/2001.

${ }^{5}$ PNS - Política Nacional de Saneamento/SEDU - Secretaria de Desenvolvimento Urbano.
} 
cício do estado na mesma gestão? b) se a competência é comum, o estado poderia exercer a sua faculdade, concorrendo com o município na outorga de concessão ou permissão dos serviços de saneamento básico? Poderia o município excluir a regulação da prestação dos serviços pelo estado, quando ele não o fizer adequadamente? Mesmo que estes potenciais conflitos possam ser resolvidos, de uma forma ou de outra, essa indefinição do arranjo institucional pode afetar o bom desempenho do setor. Esta situação só pode ser prevenida, de forma apropriada, mediante uma política descentralizada do setor, prevista em lei complementar e que, sobretudo, defina quem é o titular dos serviços de saneamento ${ }^{6}$.

Outro ponto pendente no atual modelo de gestão do setor de saneamento é a reconstituição de um sistema de financiamento. Tradicionalmente, os programas de saneamento básico têm sido financiados, ao longo das últimas décadas, com recursos de orçamentos fiscais da União, estados, distrito federal e município, do Fundo de Garantia por Tempo de Serviço (FGTS) e de empréstimos internos e externos. Os recursos do Orçamento Geral da União (OGU) são aplicados mediante doações a diversos ministérios que, por sua vez, os transfere aos outros níveis do governo, por meio de convênio, ou a órgãos da própria administração federal, como nos casos da Fundação Nacional da Saúde (FUNASA) e, no início do PLANASA, pelo BNH, Silva (1995a).

As aplicações dos estados e municípios são realizadas pelas secretarias ou outros órgãos da administração direta (Serviços e Departamentos Municipais de Água e Esgotos) ou mediante transferências dos governos aos Fundos de Água e Esgotos (FAEs) ou às Companhias Estaduais de Saneamento Básico (CESBs). Recentemente, estados e municípios também têm conseguido acesso aos empréstimos externos de agências multilaterais de crédito, especialmente do Banco Mundial e do Banco Interamericano de Desenvolvimento. Mas em termos de financiamento, o alicerce para o setor foi constituído com base nos recursos provenientes do FGTS, que compunham o SFS - Sistema Financeiro do Saneamento. No entanto, como demonstram Aliança Pesquisa e Desenvolvimento (1995) e Rezende et al (1995), a partir do final dos anos
1980 o FGTS perde gradualmente a sua capacidade de aplicação de recursos, especialmente, no setor de saneamento. A Figura 2 mostra a evolução dos investimentos no setor no período de 1990/93.

A aplicação do FGTS no setor foi realizada essencialmente no PLANASA (1971/89) e PRONURB (a partir de 1990). O volume de recursos aplicados por esses programas segue uma trajetória decrescente a partir do final dos anos 1980, depois de ter se recuperado no período de 1984-1988. De outro lado, as aplicações do governo federal tomam uma trajetória crescente, ultrapassando o volume de recursos do PRONURB em 1992.

Mais recentemente, Faria, Nogueira e Mueller (2003) mostram que a participação de recursos de fontes não-onerosas ainda é significativa. De R \$2,4 bilhōes investidos no ano de 1999 por 193 prestadores de serviços em todo o Brasil, 9,2\% dos recursos foram aplicados a fundo perdido. Esses indicadores mostram que os serviços de saneamento não têm ainda uma autonomia financeira suficiente para operar os seus serviços sem transferências da União, ou dos Estados, a fundo perdido. Com o desmantelamento do SFS e com as limitaçôes financeiras dos municípios, a situação deixa evidente a necessidade de se reconstruir um modelo de financiamento para o setor.

Um terceiro aspecto preocupante se refere à ausência de uma legislação específica para o setor, no que diz respeito às concessões dos serviços e à sua regulação. A Constituição Federal de 1988 e a Lei de Concessôes (Lei 8.987/95) ampliam a modalidade de prestação dos serviços, sendo que o titular (geralmente o município) pode prestá-los diretamente ou indiretamente por meio de concessão ou permissão a terceiros, incluindo o setor privado. A princípio, essa flexibilização constitui-se num elemento essencial para o reordenamento institucional do setor, como tem sido defendido por alguns autores (Holanda et al. 1995; IESP, 1995; Emerciano e Baltar, 1995; INFURB, 1995 e Parlatore, 2000).

A obrigação de manter o serviço em nível adequado, reconhecida constitucionalmente, implica no atendimento de, pelo menos, cinco requisitos: i) prestar o serviço a todos os usuários, sem discriminação; ii) permanência ou continuidade na área ou no período de sua vigência; iii) serviços satisfatórios, tanto em termos quantitativo, quanto qualitativo; iv) modicidade ou preços razoáveis e; v) cortesia ou bom tratamento público (IESP, 1995). No entanto, para um efetivo atendimento desses requisitos, é preciso consolidar um modelo adequado de gestão, que inclua não apenas regras disciplinadoras com relação à prestação $\mathrm{e}$ à concessão dos serviços, mas também instituir e organizar estruturas oficiais de regulação e controle (Parlatore, 2000).

Adefinição de mecanismos tarifários e de subsídios é outro aspecto pendente na atual política nacional de saneamento. No passado, um dos objetivos oficiais do PLANASA era a manutenção de tarifas com valores reais, ou seja, tarifas que tivessem valores suficientes para operar e manter os serviços e permitir o uso de subsídios cruzados entre consumidores de diferentes níveis de renda. No entanto, historicamente, os prestadores de serviços não têm conseguido manter essas tarifas em um nível adequado para cobrir os custos de operação e manutenção dos serviços. Sobre este aspecto, a INFURB (1995) mostra que, em alguns casos, os governos estaduais adotaram tarifas abaixo dos custos em nome de políticas sociais e, muita das vezes, sem transparência quanto aos subsídios praticados. Por outras vezes, as tarifas eram utilizadas como instrumentos de controle da inflação ou moeda política, reajustando-se abaixo dos índices de inflação e comprometendo o desempenho do setor.

Faria, Nogueira e Mueller (2003), mostram que essa tendência tem se mantido nos últimos anos. Os dados desse estudo comprovam que praticamente a metade das CESBs reajustaram as suas tarifas numa proporção inferior ao índice de crescimento das despesas. Considerando o total das 27 companhias, as despesas acumularam um aumento de 6\% acima dos reajustes tarifários no período de 1995 a 1999. Algumas companhias, como a SANEMAT no Mato Grosso e a CAEMA no Maranhão, chegaram a acumular diferenças de 145\% e 266\%, respectivamente, entre os seus reajustes tarifários e o aumento das despesas no período. Diante da permanência deste quadro, fica evidente também a necessidade da criação de um mecanismo legalmente instituído que estabeleça regras de reajustes tarifários e garanta o equilíbrio econômico-financeiro dos serviços.

\footnotetext{
${ }^{6}$ Segundo o INFURB (1995, p.93), na situação constitucional anterior a Constituição de 1988, os serviços de saneamento eram inequivocamente de interesse local e a questão não se apresentava de maneira tão acentuada. Exatamente em razão dessa situação, aos municípios cabia a titularidade dos serviços, sendo competência municipal a concessão dos mesmos a terceiros.
} 


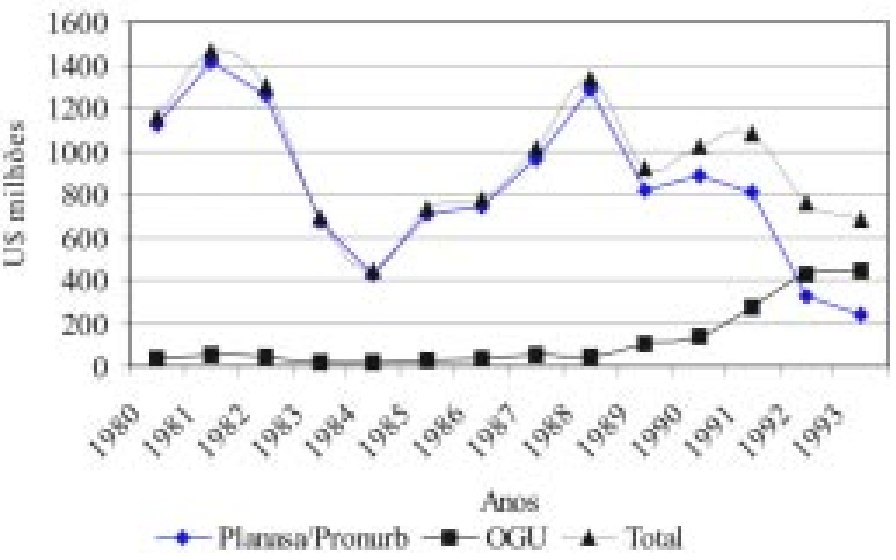

Figura 2 - Investimentos em saneamento básico com recursos do PLANASA/PRONURB e do OGU - 1980/93

Fonte: Faria, Nogueira e Mueller (2002), elaborado com base em Aliança Pesquisa e Desenvolvimento (1995) e Rezende et al (1995), a partir de dados do Balanço Geral da União e da CEF/BNH. (1) PLANASA em 1980/89 e PRONURB a partir de 1990. (2) OGU - Investimentos realizados pelo Tesouro Nacional nos subprogramas Abastecimento de Água, Saneamento Geral e Sistemas de Esgoto.

Em suma, considerando todos esses aspectos pendentes, as perspectivas para o futuro do setor se tornam pouco claras, uma vez que $o$ atual modelo de gestão ainda não está suficientemente consolidado. A ausência de uma definição legalinstitucional do modelo de gestão elucida questôes preocupantes com relação à sua capacidade de atingir a universalização dos serviços e a de acompanhar as necessidades de investimentos requeridos pelo crescimento populacional. Em poucas palavras, o que faz acreditar que esse atual modelo seja superior ao do extinto PLANASA? Com base na análise desses elementos, tudo leva a crer que seja menos eficaz ou, na melhor das hipóteses, mantenha os níveis de atendimento já alcançados.

Cenário 2: $\mathrm{O}$ modelo de gestão à luz do Projeto de Lei n. ${ }^{0}$ 4.147/2001

Dentro dos possíveis cenários para o futuro do setor, este artigo considera um caso específico, assumindo a hipótese de que o Projeto de Lei n. ${ }^{\circ}$ 4.147/2001, recentemente encaminhado à Câmara dos Deputados, venha a ser aprovado. Em essência, o referido projeto institui as diretrizes nacionais para as prestaçōes de serviços públicos de saneamento básico, de acordo com os preceitos estabelecidos pela Constituição de 1988.

De acordo com este projeto de lei, a prestação dos serviços de saneamento básico será organizada com base em bacias hidrográficas e na estrutura da rede urbana (Art. 3). Dentre os princípios fundamentais, destaca-se a necessária articulação com as políticas de desenvolvimento urbano, de recursos hídricos, de meio ambiente e de saúde. Embora seja definido de forma generalista, como qualquer princípio, deixa clara a necessidade de articulação com os demais setores e, em especial, com os recursos hídricos. Essa concepção se justifica pelo próprio envolvimento natural com os recursos hídricos, uma vez que a outorga e o uso da água para abastecimento estará condicionada às Leis Estaduais de Recursos Hídricos ou à Lei Federal 9.433/97, quando for o caso.

Um aspecto importante desse projeto se refere à titularidade dos serviços (Art.4). De acordo com essa proposta legislativa, o município é o titular dos serviços de interesse local, o Distrito Federal, em sua área geográfica, e os Estados, nos serviços de interesses comuns. Para efeito dessa lei, considera-se serviço de saneamento básico de interesse local aquele cuja atividade, infra-estrutura e instalações operacionais se destinam exclusivamente ao atendimento de um único município, integrante ou não de região metropolitana, aglomeração urbana ou microrregião. De outro lado, considera-se como sendo de interesse comum aquele serviço que, em pelo menos uma das atividades, infra-estrutura ou instalaçôes operacionais, se destine ao atendimento de dois ou mais municípios, independentemente de estarem interligados em regiāo metropolitana, aglomeração urbana ou microrregião.

Essa conceituação deixa claras as questôes relacionadas com a titularidade dos serviços. Então, se os serviços de abastecimento em um determinado município são fornecidos por uma companhia estadual, a qual investiu durante anos na atividade, o respectivo estado tornase titular do serviço. Diante dessa definição, esse município não tem autoridade para legislar sobre a matéria, pelo menos enquanto as atividades e infra-estruturas forem do Estado.

Esta condição de titularidade abrange outra situação importante. Se ao término da concessão entre o município e a CESB, a esfera local deseje retomar seus serviços por conta própria (retomar a titularidade), a solução deve ser dada mediante alguma negociação entre Estado e município no que diz respeito à infra-estrutura instalada. Isto significa que o município somente poderia recuperar a sua titularidade sobre os serviços caso ele pague ao Estado pela infra-estrutura implementada no município ou o estado, por livre iniciativa, resolva transferir o capital instalado para o município. De uma forma ou de outra, a titularidade estará amparada por lei complementar e é importante avanço para o reordenamento institucional do setor.

Com respeito ao financiamento, de um lado, o projeto de lei não prevê a criação de um fundo nacional de financiamento para o setor, como o SFS no passado. De acordo com essa proposta, a União deve repassar recursos não-onerosos aos Estados, ao Distrito Federal e aos municípios, destinados a investimentos em expansão e melhoria dos serviços. Cabe à União, promover financiamentos onerosos aos titulares ou prestadores dos serviços de qualquer natureza, dotados de autonomia gerencial e de capacidade econômica e financeira (Art 35).

Por outro lado, de forma descentralizada, a lei prevê que o titular dos serviços normatizem a criação de um fundo de universalização, com base em um percentual incidente sobre o faturamento dentro da prestadora dos serviços Art. 6). Embora essa seja uma iniciativa necessária, é atualmente insuficiente, já que pressupõe uma tarifa capaz de cobrir os custos de manutenção e operação do sistema, remunerar o capital investido e mais a parcela destinada ao fundo. No entanto, como têm de- 
monstrado as práticas tarifárias, elas não têm sido capazes de auto-sustentar a operação dos sistemas, especialmente em regiōes mais pobres. Uma grande oportunidade, não incorporada neste projeto, seria a criação de um fundo nacional de financiamento para o setor, com base nos recursos provenientes da cobrança pelo uso da água bruta (captação e lançamento de efluentes) institucionalizada pela legislação de recursos hídricos. Mesmo que esta não seja uma solução em curto prazo, pode constituir-se num sistema de financiamento autônomo, independente e sustentável em longo prazo.

Com relação aos mecanismos de determinação tarifária, o projeto de Lei prevê diversos dispositivos que tratam da questão. De acordo com a lei, toda concessão ou permissão de serviços de saneamento básico será precedida de autorização legal que lhe defina os termos e deve conter, entre outros requisitos, o regime tarifário e os procedimentos para reajustes e revisóes das tarifas (Art. 14, Parágrafo 1º, incisos VIII eXI). O próprio edital de concessão ou permissão deverá estabelecer uma estrutura tarifária básica inicial e definir os componentes dos custos para o cálculo da tarifa básica (Art. 14, Parágrafo $2^{\circ}$ ). Além do mais, os Artigos 26 e 27 estabelecem os critérios gerais para os procedimentos de reajustes tarifários, de modo a garantir o equilíbrio econômicofinanceiro da prestadora de serviços e que, ao mesmo tempo, não sejam abusivos.

No que diz respeito à regulação e às normas contratuais da prestadora de serviços, o projeto de Lei propóe um sistema descentralizado e não prevê a criação de uma agência reguladora específica para $o$ setor no âmbito nacional. $\mathrm{Na}$ esfera da Uniāo, estabelece apenas que a Agência Nacional de Águas (ANA) deve colaborar com a Secretaria Nacional de Saneamento Ambiental, determinando atribuiçōes específicas a esta agência. Em termos institucionais, o projeto prevê também a criação do Conselho Nacional de Saneamento para atuar consultivamente na definição, acompanhamento e avaliação da Política Nacional de Saneamento. Este Conselho, a ser regulamentado, deve ser composto por representantes do Governo Federal, dos Governos Estaduais e Municipais, dos prestadores e dos usuários (Art. 38).

Dentre as atribuiçóes da ANA, está a competência de exercer a coordenação nacional das atividades de regulação dos serviços de saneamento, incluindo a edição de normas e diretrizes nacionais relativas à prestação, delegação e regulação dos serviços de saneamento básico. Entre outros, compete também à ANA avaliar a presta- ção dos serviços, credenciar as entidades de regulação e de fiscalização dos serviços indicadas pelos titulares, bem como oferecer capacitação técnica e institucional para a regulação e fiscalização (Art. 41).

Dentro dessa concepção, cabe ao titular dos serviços (municípios ou estados, quando for o caso) definir a entidade responsável pela regulação e fiscalização dos serviços, exceto quando prestados diretamente por órgão ou entidade de direito público do próprio titular (Art.5, inciso VIII). Embora esse modelo possa contemplar uma aparente descentralização, duas preocupações merecem uma avaliação mais cuidadosa. De um lado, a ANA fica encarregada de avaliar todos os contratos de concessão, bem como as entidades reguladoras em nível local. Pelo menos teoricamente, o número de contratos e de entidades reguladoras podem convergir para o mesmo número de municípios existentes no país, o que dificultaria o controle da ANA. De outro lado, a criação de uma entidade reguladora e fiscalizadora em nível local pressupõe a existência de um município com grande capacitação técnica e financeira, o que é irreal para a maior parte dos casos. Então, essa contradição, não facilmente solucionável, abre espaço para futuras distorções do modelo, permitindo, em determinados municípios, a exploração dos serviços pelo setor privado de forma abusiva e em comum acordo com o poder político local.

Em suma, na hipótese de aprovação do projeto de Lei n. ${ }^{\circ} 4.147 / 2001$, o modelo de gestão para o setor de saneamento se torna mais consolidado. Além de estabelecer diretrizes gerais para a prestação dos serviços de saneamento, sobretudo as condiçóes de concessão ou permissão ao setor privado, esclarece a titularidade dos serviços com base numa definição clara do que seja interesse local e interesse comum, conceitos essenciais para ações de competência comum entre União, Estados e municípios. O projeto inova o modelo de gestão ao normatizar também as interfaces do setor com outros setores correlatos, especialmente o de recursos hídricos.

No entanto, mesmo sob a concretização dessa hipótese, o modelo de gestão não fica totalmente fechado. Uma questão-chave se refere à indefinição de um fundo específico a nível nacional para o financiamento do setor, o que deixa o saneamento dependente de fontes tradicionais de recursos provenientes das dotaçōes orçamentárias da União. Outro ponto preocupante é uma potencial contradição existente entre a responsabilidade e a capacidade dos titulares de criarem suas próprias agências de regulação e de fiscalização local e a responsabilidade da ANA, em nível federal, coordenar e controlar todas as concessóes.

\section{CONSIDERAÇÕES FINAIS}

Este artigo faz uma análise das perspectivas para o setor de saneamento, enfocando a sua interface com o setor de recursos hídricos. Além de uma descrição sumária dos atuais modelos de gestão de ambos os setores, a discussão mostra que há algumas limitaçôes institucionais para o abastecimento urbano de água e esgotamento sanitário. Essa análise é feita distinguindo-se dois cenários: o primeiro é constituído tomando-se como base o status quo da atual gestão de saneamento e o segundo parte da suposição de uma eventual aprovação do Projeto de Lei n. ${ }^{\circ} 4.147 / 2001$, que tem a finalidade de consolidar um novo modelo de gestão para o setor e de normatizar sua interface com os recursos hídricos.

Considerando o atual cenário da política nacional de saneamento, o artigo mostra que a pendência de alguns aspectos institucionais e legais deixa o modelo de gestão numa condição de pouca eficácia. Dentre esses elementos, o artigo discutiu a importância da necessidade de uma Lei que trate do ajuste das competências entre as esferas do governo, a necessidade de instrumentos jurídicos-legais que disponham sobre a regulação e a fiscalização de serviços sob concessão, a necessidade da reconstrução de um fundo de investimentos para o setor, bem como a importância de normatizar os procedimentos de revisão tarifária. Embora a importância desses elementos seja reconhecida pelas próprias autoridades competentes, em particular da antiga Secretaria Especial de Desenvolvimento Urbano, o governo federal não tem conseguido mobilizar forças políticas suficientes para solucionar e consolidar um modelo de gestão para o setor. Se esse modelo é mantido, não há nada de substancial que faça acreditar na melhoria dos níveis de atendimento para os próximos anos. Do ponto de vista institucional, esse arranjoéinferior ou, na melhor das hipóteses, similar ao modelo PLANASA durante o seu período de desmantelamento no final da década de 1980.

Sob a hipótese de uma aprovação do Projeto de Lei n. ${ }^{\circ}$ 4.147/2001, o cenário se torna significativamente mais 
promissor. Em linhas gerais, o projeto propõe diretriz básica para a prestação dos serviços de saneamento e, em particular, as condições de concessão ou permissão ao setor privado, estabelece as regras para definição da titularidade dos serviços, bem como normatiza a interface com o setor de recursos hídricos. No entanto, mesmo sob essas condições, o trabalho discute a existência de uma potencial contradição existente entre o princípio de descentralização dos sistemas de concessão e o princípio de controle centralizado na Agência Nacional de Águas. Além do mais, o projeto não prevê a criação de um fundo nacional de financiamento para o setor, o que deixa o sistema vulnerável às disponibilidades incertas de dotações orçamentárias da União.

\section{REFERÊNCIAS}

ALIANÇA PESQUISA E DESENVOLVIMENTO. Diagnóstico do Setor Saneamento: estudo econômico e financeiro. Brasília: Ministério do Planejamento e Orçamento. Secretaria de Política Urbana/IPEA, 251p. (Série Modernização do Setor Saneamento, v. 4), 1995b.

AZEVEDO, L.G.T. e BALTAR, A. M. Nota técnica sobre a atuação do Banco Mundial no gerenciamento de recursos hidricos no Brasil. In: MUÑOZ, Héctor Raúl (org). Interfaces da gestão de recursos Hídricos - Desafios da Lei de Águas de 1997. MMA/SRH, 2000.

PERREIRA, L. C. B. A reforma do Estado nos anos 90: lógica e mecanismos de controle. Brasília, Cadernos MARE da Reforma do Estado, 1997.

CARRERA-FERNANDEZ, J.C. A valorização da água e a cobrança pelo uso. Salvador: UFB/FCE/CME, 2000.
EMERCIANO, E. e BALTAR, L.A. Flexibilização Institucional da prestação de serviços de saneamento: implicaçōes e desafios. Brasília: Ministério do Planejamento e Orçamento. Secretaria de Política Urbana. /IPEA, (Série Modernização do Setor Saneamento, 3), 1995.

FARIA, R. C; NOGUEIRA, J.M. e MUELLER, B.P. Politicas de precificação do setor de saneamento urbano no Brasil: as evidências do Equilibrio de Baixo Nivel. Brasília: UnB/Departamento de Economia, workpaper, 2003.

HOLANDA, N. C. et al. Regulação da prestação de serviços de saneamento: análise comparada da legislação Internacional.Brasília: Ministério do Planejamento e Orçamento. Secretaria de Política Urbana/IPEA, 278 p. (Série Modernização do Setor Saneamento, 6), 1995.

INFUB - Núcleo de Pesquisa em Informaçōes Urbanas da Universidade de São Paulo. Fundamentos e proposta de ordenamento institucional. Brasília: Ministério do Planejamento e Orçamento. Secretaria de Política Urbana/IPEA, (Série de Modernização do Setor Saneamento, 1), 1995a.

IESP - Instituto de Economia do Setor Público. Proposta de regulamentação de serviços de saneamento. Brasília: Ministério do Planejamento e Orçamento. Secretaria de Política Urbana/IPEA, 168p. (Série Modernização do Setor de Saneamento, 5), 1995.

KETTELHUT, J.T.S. et al. Cobrança e outorga pelo usos da água. In: FREITAS, M. A. V. (org). O estado das águas no Brasil. Brasília: ANEEL, SIH; MMA, SRH; MME, 1999.

MUÑOZ, H.R. Razões para um debate sobre as interfaces da gestão dos recursos hidricos no contexto da lei de águas de 1997. In: MUÑOZ, H.R. (org). Interfaces da gestão de recursos hídricos - Desafios da Lei de Águas de 1997. Brasília: Ministério do Meio Ambiente/Secretaria dos Recursos Hídricos, 2000.

PAGNOCCHESCHI, B. A Politica Nacional de Recursos Hídricos no cenário da integração das politicas públicas. In: MUÑOZ, H.R. (org).
Interfaces da gestão de recursos Hídricos - Desafios da Lei de Águas de 1997. Brasília: Ministério do Meio Ambiente/Secretaria dos Recursos Hídricos, 2000.

PARLATORE, A.C. Privatização do setor de saneamento no Brasil. Rio de Janeiro: BNDES, 2000 .

PEREIRA, D. S. P. e BALTAR, L. A. A. Saneamento e recursos hidricos: os desafios da integração e a urgência da prioridade. In: MUÑOZ, H.R. (org). Interfaces da gestão de recursos hídricos - Desafios da Lei de Águas de 1997. Brasília: Ministério do Meio Ambiente/Secretaria dos Recursos Hídricos, 2000.

PEREIRA, D. S. P; BALTAR, L.A.A. e ABICALIL, M.T. Saneamento: modernização e parceria com o setor privado. Brasília: Ministério do Planejamento e Orçamento. Secretaria de Política Urbana/IPEA, (Série Modernização do Setor Saneamento, 9), 1995.

REZENDE, F. et al. Novo Modelo de Financiamento para o setor saneamento. Brasília: Ministério do Planejamento e Orçamento. Secretaria de Política Urbana/IPEA. (Série Modernização do Setor Saneamento, v. 2), 1995.

\section{Endereço para correspondência:}

\section{Simone Alves de Faria \\ SQN 2 I 4, Bloco I, Apt. 307 \\ 70873-090 - Brasília - DF - Brasil \\ Tel.: (6I) 2727429 \\ E-mail: sadefaria@ hotmail.com}

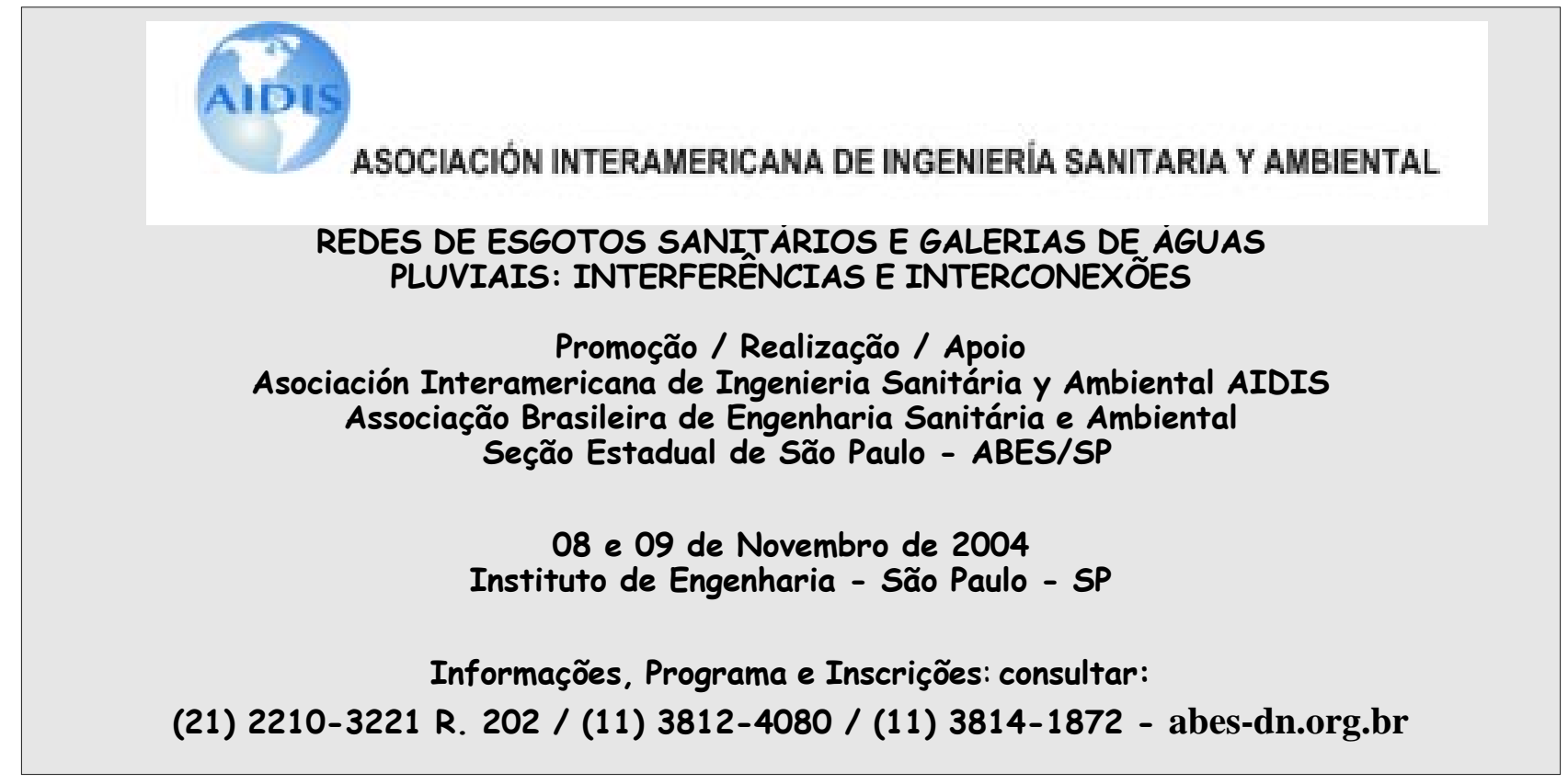

